\title{
First report of venereal and vertical transmission of canine leishmaniosis from naturally infected dogs in Germany
}

Torsten J Naucke $\mathrm{e}^{1,2,3^{*}}$ and Susanne Lorentz ${ }^{1}$

\begin{abstract}
Background: Canine leishmaniosis (CanL) is a zoonotic disease caused by Leishmania (L.) infantum. It is endemic to several tropical and subtropical countries but also to the Mediterranean region. It is transmitted by phlebotomine sandflies but occasional non-vector transmissions have been reported, including vertical and horizontal transmission.
\end{abstract}

Findings: The authors report a case of CanL in a female boxer dog from Dusseldorf, Germany, that had never been in an endemic region. A serum sample from the bitch was tested positive for antibodies against Leishmania (IFAT 1:2,000, ELISA 72). The bitch had whelped three litters, and one puppy from the third litter was also found to be seropositive for Leishmania antibodies (IFAT 1:4,000, ELISA 78).

Conclusions: Up to now, despite intensive searching, the occurrence of sandflies could not be proved in the bitch's region of origin. Thus, vertical and horizontal transmission are to be discussed as possible ways of infection. This may be the first report of venereal and vertical transmission of L. infantum in naturally infected dogs in Germany.

Keywords: Leishmaniosis, Venereal transmission, Vertical transmission, Dog, Germany

\section{Findings}

Canine leishmaniosis (CanL) caused by Leishmania (Leishmania) infantum (or its New World synonym Leishmania (L.) chagasi) is a zoonotic disease of major public health and veterinary importance with a wide geographical distribution. It is endemic in Mediterranean countries and in regions of Africa, Asia, South and Central America [1]. But CanL is also an important concern in non-endemic regions. In Germany, increasing numbers of dogs are becoming infected by L. infantum as a result of travelling to Mediterranean countries, or being imported from these regions. It is estimated that there are 20,000 infected dogs in Germany [2]. Canine infection is associated with variable clinical manifestations, ranging from unapparent subclinical infections to fatal visceralizing disease. Clinical signs include generalized lymphadenomegaly, hepatomegaly, splenomegaly,

\footnotetext{
* Correspondence: TJNaucke@aol.com

${ }^{1}$ Parasitus Ex e.V., Vollbergstraße 37, Niederkassel 53859, Germany

Full list of author information is available at the end of the article
}

fever, diarrhea, lethargy, and progressive weight loss $[3,4]$. Furthermore the majority of dogs show skin lesions. It is primarily a dry, exfoliative dermatitis. Further common prevalent symptoms are ulcerating skin lesions, as, for example, at the outer edge of the ear or the nose [4]. Common clinical chemistry abnormalities include hyperproteinemia observed with hypergammaglobulinemia and hypoalbuminemia [5].

In spring 2011, a 7-year-old female boxer was presented in a veterinary clinic due to an exfoliative dermatitis with ulcerations on the external ears. The owners had observed that the dog became lethargic and inactive. The dog had never left the Dusseldorf region of Germany other than for a short stay in Denmark in 2005. The bitch had whelped three litters (2008 4 male, 2 female puppies; 20093 male puppies; 20102 male, 3 female puppies) from two stud dogs. In May 2011, cutaneous samples were collected at the veterinary clinic from diseased skin of the ears and of a nodular lesion at the hind limb. Histologically a lymphoplasmacytic and

\section{Biomed Central}


histiocytic inflammation, with few intracellular amastigotes in macrophages, was present. Additionally, examination of the cutaneous lesions revealed a malignant lymphoma; atypical lymphoid cells were shown to be CD3-positive in the immunohistochemical analysis. Laboratory studies revealed hyperproteinemia $(89.6 \mathrm{~g} / \mathrm{l}$, reference interval 54-75 g/l), hypergammaglobulinemia (31.6\%, reference interval 8-18\%), hypoalbuminemia (37.1\%, reference interval $47-59 \%)$, and a marginal decreased albumin/globulin-ratio $(0.59$, reference interval 0.59-1.11). Serologic tests, conducted in July 2011, included an enzyme-linked immunosorbent assay (ELISA, cutoff value $>5$ antibody units; ELISA based on soluble promastigote antigen in combination with immunoglobuline $\mathrm{G}(\gamma)$-specific conjugate [6]) and an indirect fluorescent antibody technique (IFAT, cutoff value $>1: 50$, MegaScreen $^{\circledR}$, MegaCor, Austria). Because IFAT sensitivity and specificity are near $100 \%$, the test is considered by World Organization for Animal Health (OIE-Office International des Epizooties) as a reference serologic method [7]. The serum sample of the bitch was tested positive for antibodies against Leishmania (ELISA 72, IFAT 1:2,000). Furthermore all of the bitch's puppies were tested serologically in June 2011 and July 2011 respectively (IFAT and ELISA). One puppy of the third litter, who had never left the greater area of origin, was also found to be seropositive for Leishmania antibodies (ELISA 78, IFAT 1:4,000). To confirm the diagnosis of CanL in the bitch and the mentioned puppy, serum protein electrophoresis was carried out. In both cases the electrophoretic patterns revealed a hypergammaglobulinemia, a characteristic feature of CanL (Figure 1).

Based on the present investigative results, the bitch was treated with Allopurinol $(20 \mathrm{mg} / \mathrm{kg}$ per day). The diagnosed T-cell lymphoma was not treated separately. The dog recovered well under the influence of the therapy and showed a good general condition ever since the beginning of the treatment.

This case of CanL demonstrates that a medical history negative for traveling to known endemic areas is insufficient to exclude CanL as a possible diagnosis. Infections with $L$. infantum in a child, as well as in a horse and dogs who had never left Germany, have already been described [8-10]. Although CanL is usually transmitted via a phlebotomine sandfly vector, alternative routes of transmission, including vertical transmission and horizontal (via direct blood to blood or sexual contact) transmission have been reported [8,11-16]. Possible modes of transmission in the reported case are discussed below.

Studies have provided evidence for the natural occurrence of sandflies in Germany. Various specimens of Phlebotomus (P.) mascittii were caught in different locations in Baden- Wurttemberg and one specimen near
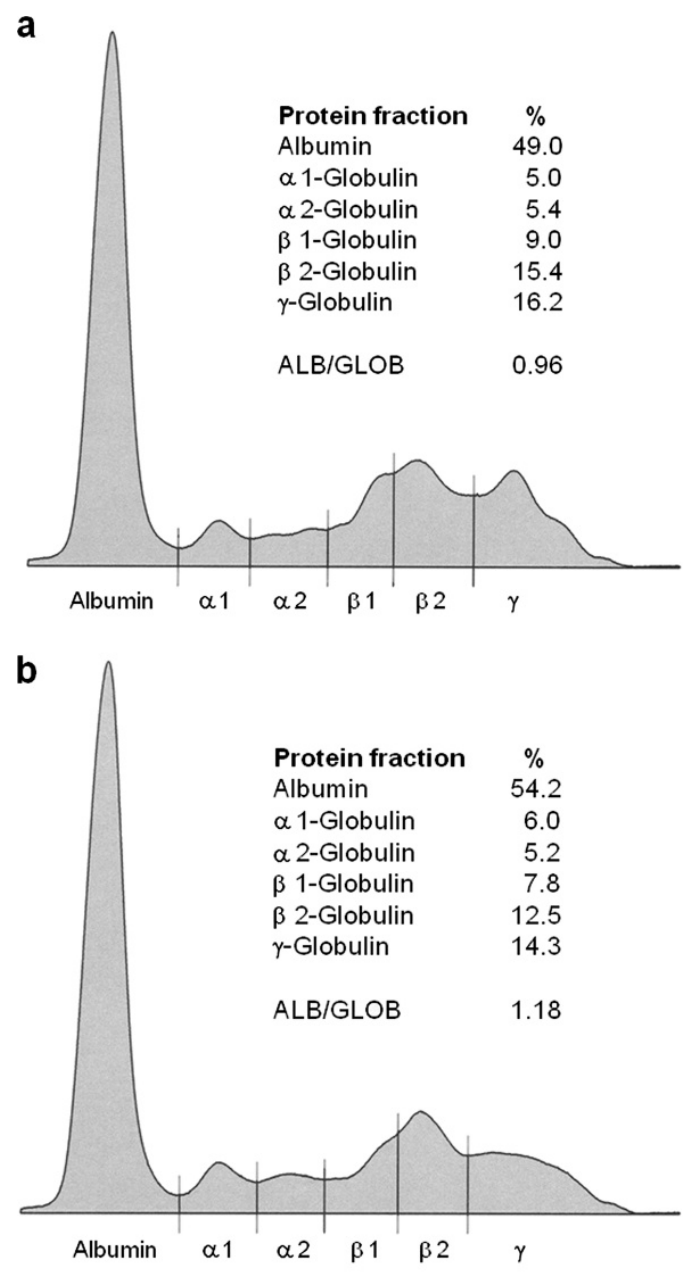

C

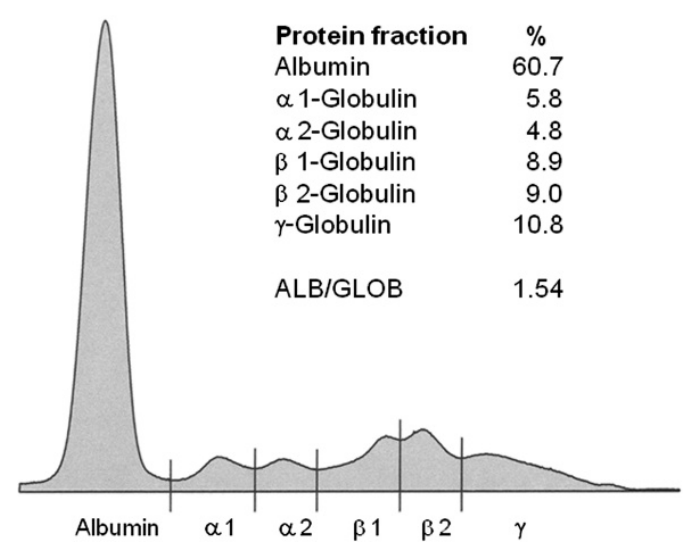

Figure 1 Serum electrophoretic patterns and serum protein levels in the bitch and two puppies from the third litter. The bitch (a) and one puppy from the third litter (b) were tested positive for antibodies against Leishmania (IFAT, ELISA). Serum protein electrophoresis revealed in both cases a characteristic hypergammaglobulinemia. The serum protein electrophoresis from the sample of a puppy tested negative for Leishmania antibodies (c) showed a gammaglobulin level within the normal range. 


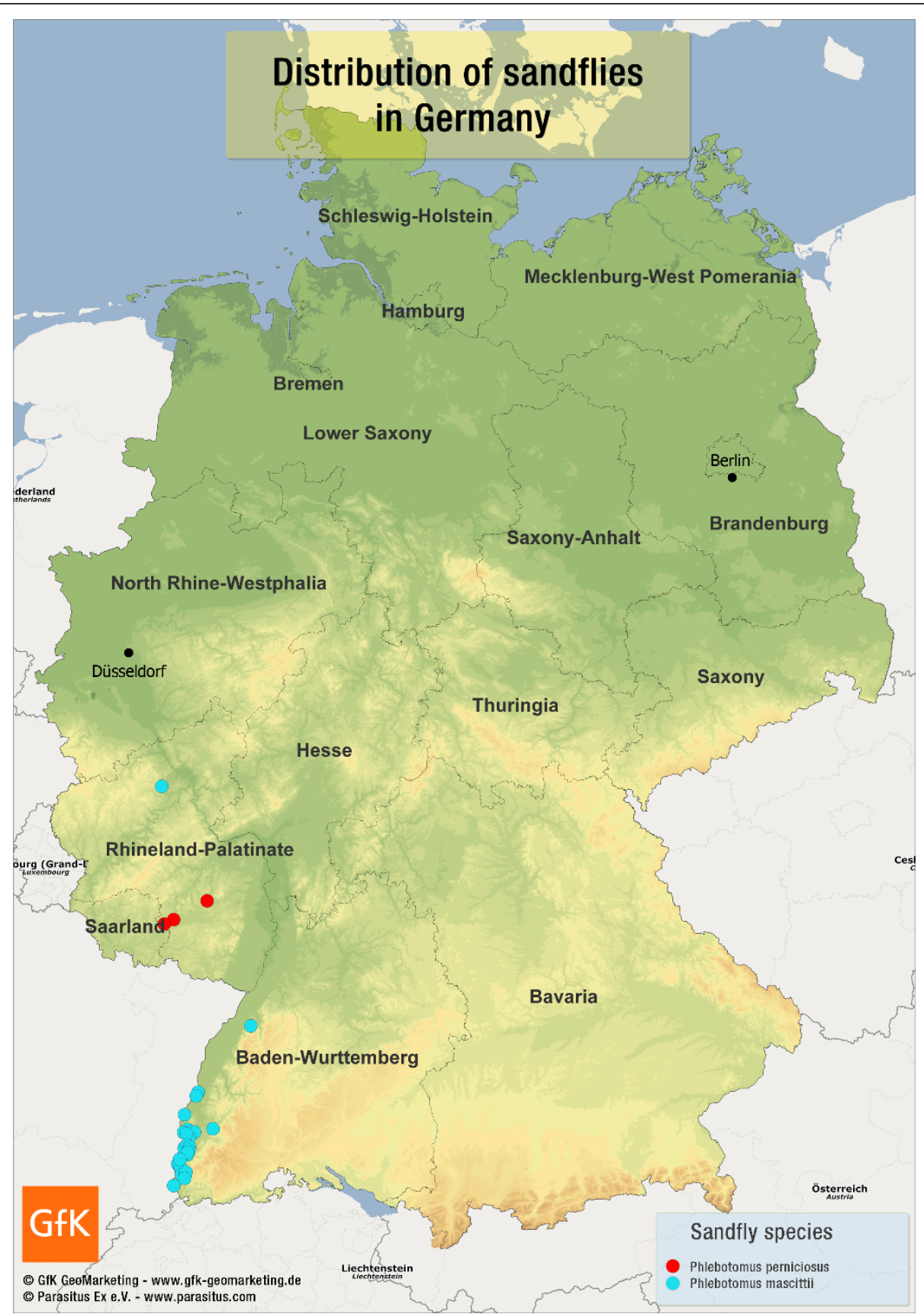

Figure 2 Known geographical distribution of sandflies in Germany. Various specimens of Phlebotomus mascittii were caught in different locations in Baden-Wurttemberg and one specimen near Cochem on the Mosel river. In addition, Phlebotomus perniciosus was detected in Germany near Kaiserslautern (Rhineland-Palatinate) $[2,17]$.

Cochem on the Mosel river. In addition, Phlebotomus (P.) perniciosus was detected near Kaiserslautern (Rhineland-Palatinate) [2,17] (Figure 2). Although P. mascittii has not yet been confirmed as a vector of leishmaniasis, its competence is suspected [2]. It is noteworthy that one specimen of $P$. perniciosus, the main vector of $L$. infantum, had been captured in 1923 in Jersey, Channel Islands, United Kingdom [18]. However, intensive searching by the authors of this short report on location since 2010 could not provide any further evidence for the natural occurrence of sandflies in that region (Naucke, unpublished observations).

Despite the installation of over one hundred sandfly traps in the greater area of Cologne/Dusseldorf/Bonn since 1999, no sandflies could be detected up to this point (Naucke, unpublished observations). This fact 
does not fully exclude a possible transmission of CanL via sandflies to the bitch; however, it is only with the smallest of probabilities that a sandfly transmitted the infection.

Venereal transmission has to be considered as another possible route of infection. In fact, naturally infected male dogs often develop genital lesions, particularly in the epididymis, prepuce, and glans penis and infected dogs are capable of shedding Leishmania in the semen [19]. In 2009, a study supported the notion that Leishmania may be sexually transmitted from naturally infected dogs to susceptible bitches: Twelve Leishmaniafree bitches, housed in the absence of the insect vector, copulated with multiple infected dogs, that were shedding Leishmania in the semen. By the end of the experimental period, three bitches seroconverted and six were PCR positive [14]. In this reported case, both dogs that copulated with the bitch may be considered as possible vectors. The father of the first two litters died in 2010 at the age of 10 years. Stopovers in Bulgaria, Slovenia and Croatia among others for different dog shows, in addition to an artificial insemination center in Malaga, southern Spain, permit the suspicion that the dog became infected during one of these stays. Noteworthy is the especially high canine seroprevalence of CanL of $34.6 \%$ in the Axarquía region, Malaga province. In the Axarquía region, dogs belonging to short-haired breeds (boxer, setter, among others) also show a significant higher seroprevalence than those belonging to longhaired breeds [20]. The third litter's father is still alive and used for breeding. Because the CanL was only diagnosed in the bitch after the mating, a transmission of the parasite from the third litter's father to the bitch can also not be fully excluded. An inverted way of infection from the bitch to the male dogs is, from today's current knowledge, most improbable as a genital tropism of Leishmania has not be unequivocally proved in female dogs so far [21].

A vertical transmission of the parasite to the bitch cannot definitively be excluded, not least because the bitch herself obviously infected one of her puppies of the third litter with the parasite. The possibility of transplacental transmission of CanL is based on the circulating parasites within macrophages. The placental blood supply is in close proximity to the maternal circulation, and parasites might pass into fetal circulation [22]. Recently, two reports demonstrated vertical transmission of $L$. infantum in naturally infected dogs in a non-endemic region (North America) [11] and in an endemic region (Brazil) [13]. In North America, the vertical transmission is even discussed as a main mechanism for autochthonous cases of CanL in the foxhound population [11].
The data presented here poses new challenges and considerations for the control of CanL transmission. Disease prevention methods that solely target the vector, such as the use of repellents or avoiding travelling to endemic areas, may not be sufficient to control disease dissemination. Other methods should be considered in endemic and non-endemic regions, such as an enlargement of the breeding criteria regarding the absence of venereal or vertical transmissible infections in the dogs. That way a proven infection with CanL might be a reason for excluding dogs from professional breeding. For the future this might be especially relevant for those countries where the number of infected dogs are reaching alarming proportions, owing not only to transporting these animals to endemic areas but also due to the import of infected animals.

\section{Acknowledgements}

This work was supported by Bayer Animal Health $\mathrm{GmbH}$ as well as Parasitus Ex e.V.

\section{Author details}

${ }^{1}$ Parasitus Ex e.V., Vollbergstraße 37, Niederkassel 53859, Germany.

${ }^{2}$ Department of Zoology, Division of Parasitology, University of Hohenheim, Stuttgart 70599, Germany. 'aboklin GmbH \& Co. KG, Steubenstraße 4, Bad Kissingen 97688, Germany.

\section{Authors' contributions}

Both authors have contributed substantially to this report. TJN collected the data and drafted the manuscript. SL carried out all laboratory examinations and helped to write the manuscript. Both authors have read and approved the final manuscript.

\section{Competing interests}

The authors declare that they have no competing interests.

Received: 12 January 2012 Accepted: 1 April 2012

Published: 1 April 2012

\section{References}

1. Baneth G, Koutinas AF, Solano-Gallego L, Bourdeau P, Ferrer L: Canine leishmaniosis-new concepts and insights on an expanding zoonosis: part one. Trends Parasitol 2008, 24:324-330.

2. Naucke TJ, Menn B, Massberg D, Lorentz S: Sandflies and leishmaniasis in Germany. Parasitol Res 2008, 103(Suppl 1):S65-S68.

3. Solano-Gallego L, Miró G, Koutinas A, Cardoso L, Pennisi MG, Ferrer L, Bourdeau P, Oliva G, Baneth G, The LeishVet Group: LeishVet guidelines for the practical management of canine leishmaniosis. Parasit Vectors 2011, $4: 86$.

4. Moritz A: Leishmaniose. In Klinik der Hundekrankheiten.. 3 edition. Edited by: Grünbaum EG, Schimke E Stuttgart. Enke MVS Medizinverlage; 2007:1140-1145.

5. Petersen CA: Leishmaniasis, an emerging disease found in companion animals in the United States. Top Companion Anim Med 2009, 24:182-188.

6. Mettler M, Grimm F, Capelli G, Camp H, Deplazes P: Evaluation of enzymelinked immunosorbent assays, an immunofluorescent-antibody test, and two rapid tests (Immunochromatographic-Dipstick and Gel Tests) for serological diagnosis of symptomatic and asymptomatic leishmania infections in dogs. J Clin Microbiol 2005, 43:5515-5519.

7. Gradoni L, Gramiccia M: Leishmaniasis. OIE manual of standards for diagnostic tests and vaccine. 4 edition. Paris, France: Office International des Epizooties; 2000, 802-812.

8. Bogdan C, Schönian G, Bañuls AL, Hide M, Pratlong F, Lorenz E, Röllinghoff M, Mertens R: Visceral leishmaniasis in a German child who 
had never entered a known endemic area: case report and review of the literature. Clin Infect Dis 2001, 32:302-306.

9. Koehler K, Stechele M, Hetzel U, Domingo M, Schönian G, Zahner H, Burkhardt E: Cutaneous leishmaniosis in a horse in southern Germany caused by Leishmania infantum. Vet Parasitol 2002, 109:9-17.

10. Gothe R: Leishmaniosen des Hundes in Deutschland: Erregerfauna und -biologie, Epidemiologie, Klinik, Pathogenese, Diagnose, Therapie und Prophylaxe. Kleintierpraxis 1991, 36:69-84.

11. Boggiatto PM, Gibson-Corley KN, Metz K, Gallup JM, Hostetter JM, Mullin K, Petersen CA: Transplacental transmission of Leishmania infantum as a means for continued disease incidence in North America. PLoS Negl Trop Dis 2011, 5:e1019.

12. Rosypal AC, Troy GC, Zajac AM, Frank G, Lindsay DS: Transplacental transmission of a North American isolate of Leishmania infantum in an experimentally infected beagle. J Parasitol 2005, 91:970-972.

13. da Silva SM, Ribeiro VM, Ribeiro RR, Tafuri WL, Melo MN, Michalick MSM: First report of vertical transmission of Leishmania (Leishmania) infantum in a naturally infected bitch from Brazil. Vet Parasitol 2009, 166:159-162.

14. Silva FL, Oliveira RG, Silva TMA, Xavier MN, Nascimento EF, Santos RL: Venereal transmission of canine visceral leishmaniasis. Vet Parasitol 2009, 160:55-59.

15. Pangrazio KK, Costa EA, Amarilla SP, Cino AG, Silva TMA, Paixão TA, Costa LF, Dengues EG, Diaz AAR, Santos RL: Tissue distribution of Leishmania chagasi and lesions in transplacentally infected fetuses from symptomatic and asymptomatic naturally infected bitches. Vet Parasitol 2009, 165:327-331.

16. Owens SD, Oakley DA, Marryott K, Hatchett W, Walton R, Nolan TJ, Newton A, Steurer F, Schantz P, Giger U: Transmission of visceral leishmaniasis through blood transfusions from infected English foxhounds to anemic dogs. J Am Vet Med Assoc 2001, 219:1076-1083.

17. Naucke TJ, Schmitt C: Is leishmaniasis becoming endemic in Germany? Int J Med Microbiol 2004, 293(Suppl 37):179-181.

18. Marett P: A note on the capture of a Phlebotomus perniciosus male in Jersey. C.I. Transactions of the Royal Society of Tropical Medicine and Hygiene 1923, 17:267.

19. Diniz SA, Melo MS, Borges AM, Bueno R, Reis BP, Tafuri WL, Nascimento EF, Santos RL: Genital lesions associated with visceral leishmaniasis and shedding of Leishmania sp. in the semen of naturally infected dogs. Vet Pathol 2005, 42:650-658.

20. Morillas F, Sanchez Rabasco F, Ocaña J, Martin-Sanchez J, Ocaña-Wihelmi J, Acedo C, Sanchiz-Marin MC: Leishmaniosis in the focus of the Axarquía region, Malaga province, southern Spain: a survey of the human, dog, and vector. Parasitol Res 1996, 82:569-570

21. Silva FL, Rodrigues AAM, Rego IOP, Santos RLH, Oliveira RG, Silva TMA, Xavier MN, Nascimento EF, Santos RL: Genital lesions and distribution of amastigotes in bitches naturally infected with Leishmania chagasi. Vet Parasitol 2008, 151:86-90.

22. Rosypal AC, Lindsay DS: Non-sand fly transmission of a North American isolate of Leishmania infantum in experimentally infected BALB/c mice. J Parasitol 2005, 91:1113-1115.

doi:10.1186/1756-3305-5-67

Cite this article as: Naucke and Lorentz: First report of venereal and vertical transmission of canine leishmaniosis from naturally infected dogs in Germany. Parasites \& Vectors 2012 5:67.

\section{Submit your next manuscript to BioMed Central and take full advantage of:}

- Convenient online submission

- Thorough peer review

- No space constraints or color figure charges

- Immediate publication on acceptance

- Inclusion in PubMed, CAS, Scopus and Google Scholar

- Research which is freely available for redistribution

Submit your manuscript at www.biomedcentral.com/submit
Biomed Central 